\title{
NOTA SÔBRE 0 SISTEMA RADICULAR DO GANDU, Cajanus cajan (L.) MILLSP., E A SUA IMPORTÂNCIA NA ADUBAÇÃOO VERDE
}

\section{Romeu Inforzato}

O grande valor das leguminosas como adubo verde não está apenas no enriquecimento proporcionado ao solo em matéria orgânica, indispensável ao melhoramento de suas propriedades físicas e químicas. Há um refôrço em azôto, conseguido pelas bactérias, vivendo em simbiose nos nódulos das raízes dessas plantas.

O estudo comparativo da massa verde produzida pelas partes aéreas das diversas leguminosas é relativamente fácil $(\mathbf{1}, \mathbf{2})$.

A avaliação da quantidade de matéria orgânica incorporada ao solo pelas raízes das plantas utilizadas como adubo verde, é problema mais delicado. Requer técnica especial $(2,3)$.

Cajanus cajan (L.) Millsp., (Cajanus indicus Spreng.), é por alguns tida como originária da Índia, por outros como da Árica (1). A data de sua introdução no Estado de São Paulo ainda não foi definida.

E planta de múltiplas aplicações (1). Entre nós se destaca como forragem verde para o gado, e pela sua aplicação na restauração dos solos cansados.

\section{MATERIAL E TECNICA}

$O$ material de que nos servimos para o presente estudo, foi plantado pelo nosso colega Antônio José de Sousa, em Novembro de 1944, em solo do tipo terra roxa misturada, na Estação Experimental Central (Santa Elisa), Campinas. A plantação foi feita em linhas, com os espaçamentos de $0,50 \mathrm{~m}$ nas entrelinhas e $0,10 \mathrm{~m}$ nas linhas. $\mathrm{Na}$ ocasião do estudo, as plantas tinham, aproximadamente, 2 anos de idade. Escolhemos 8 plantas em linha, cuja altura média foi $4,5 \mathrm{~m}$ e que representavam o tipo médio das plantas do lote.

Foi empregada a mesma técnica usada nos estudos dos sistemas radiculares do cafeeiro e da tefrósia (2), (3), isto é, escolhidas as 8 plantas, foram cortadas rente ao solo. A $0,25 \mathrm{~m}$ dos tocos, abriu-se uma valeta paralela à linha das plantas. A profundidade desta valeta foi até onde não mais se percebessem raízes do feijão guandu. A largura foi mais ou menos de $1,5 \mathrm{~m}$, espaço suficiente para que os operários nêle pudessem trabalhar comodamente com suas ferramentas. A parede da valeta do lado onde permaneceram as raízes das plantas cortadas, foi preparada a fim de ficar bem plana e vertical ; em seguida, foi desmanchada em blocos. Sendo o terreno plano, 
não existiu uma primeira camada de blocos com alturas variáveis como nos trabalhos anteriores (2 e 3). Assim, tiraram-se as 3 primeiras camadas de blocos com $0,15 \mathrm{~m}$ de altura ; as duas seguintes, com $0,25 \mathrm{~m}$ e as 4 últimas, com $0,50 \mathrm{~m}$ de altura cada.

A parede, com $4 \mathrm{~m}$ de comprimento por $2,95 \mathrm{~m}$ de profundidade e $0,50 \mathrm{~m}$ de largura, foi completamente desmanchada em 72 blocos, sendo 24 com $0,15 \mathrm{~m}$ de alto, $16 \mathrm{com} 0,25 \mathrm{~m}$ e, finalmente, $32 \mathrm{com} 0,50 \mathrm{~m}$ de altura.

Cada bloco retirado foi colocado em um saco, devidamente etiquetado para indicar sua correspondente posição na parede. Terminada a coleta dos blocos, êstes foram desfeitos e peneirados para separar as raízes da terra ; em seguida, estas foram lavadas e sêcas à sombra durante um dia, e depois pesadas com aproximação de $0,1 \mathrm{gr}$.

Obtidos êstes dados, pudemos reconstruir a distribuição dos sistemas radiculares das 8 plantas do feijão guandu pelas diferentes camadas do solo e exprimir estas distribuições em percentagem.

Pudemos também determinar a profundidade atingida pelas raízes.

$O$ pêso total das raízes das 8 plantas estudadas foi de $1.237,04 \mathrm{gr}$ e o das partes aéreas 17.200 gr. Do pêso total das raízes, $90,67 \%$ se encontravam na camada de solo constituída pelos primeiros $0,30 \mathrm{~m}$ de profundidade. O restante, $9,33 \%$, estava entre esta última profundidade e a profundidade máxima alcançada pelas raízes e que foi de $2,95 \mathrm{~m}$. A esta apreciável profundidade e homogênea distribuição das raízes, como se observa na figura 1, é que atribuímos a grande resistência do feijão guandu à sêca. E bem conhecido o fato de esta planta se apresentar sempre verde durante estiagens prolongadas, o que lhe confere apreciável valor como forrageira verde.

De acôrdo com os dados obtidos, o feijão guandu, utilizado como adubo verde, aos dois anos de idade mais ou menos, plantado em linhas, com espaçamento de $0,50 \mathrm{~m}$, na terra roxa misturada de Campinas, forneceu ao solo $6.185 \mathrm{~kg}$ de raízes por hectare, ou $14.968 \mathrm{~kg}$ por alqueire paulista, dos quais $13.571 \mathrm{~kg}$ se achavam na camada de solo compreendida pelos primeiros $0,30 \mathrm{~m}$ de profundidade. Se bem que esta quantidade não seja despresível, é pequena quando comparada com a matéria orgânica fornecida pelas partes aéreas que, segundo os nossos cálculos, produziu $208.124 \mathrm{~kg}$ por alqueire. Tem, porém, a seu favor, o fato de ser deixada já enterrada no solo, ser distribuída a uma maior profundidade e, pelo apodrecimento, deixar no solo um número elevadíssimo de canalículos, que, sem dúvida, muito concorrem para melhoria da terra.

\section{LITERATURA CITADA}

1. Anonimo. O Guandu e suas utilizaçoes. Comunicado da Seçãa de Cereais e Leguminosas, Instituto Agronômico do Estado, mimeografado, pg. 1-4, sem data.

2. Franco, C. M. e R. Inforzato. O sistema radicular do cafeeiro nos principais tipos de solo do Estado de São Paulo. Bragantia 6 : 443-478, figs. 1-8, graf. 1-15. 1946.

3. Inforzato, R. Estudo do sistema radicular de Tephrosia candida D. C. Bragantia 7 : 47-52, fig. 1, est. 14-15. 1947. 


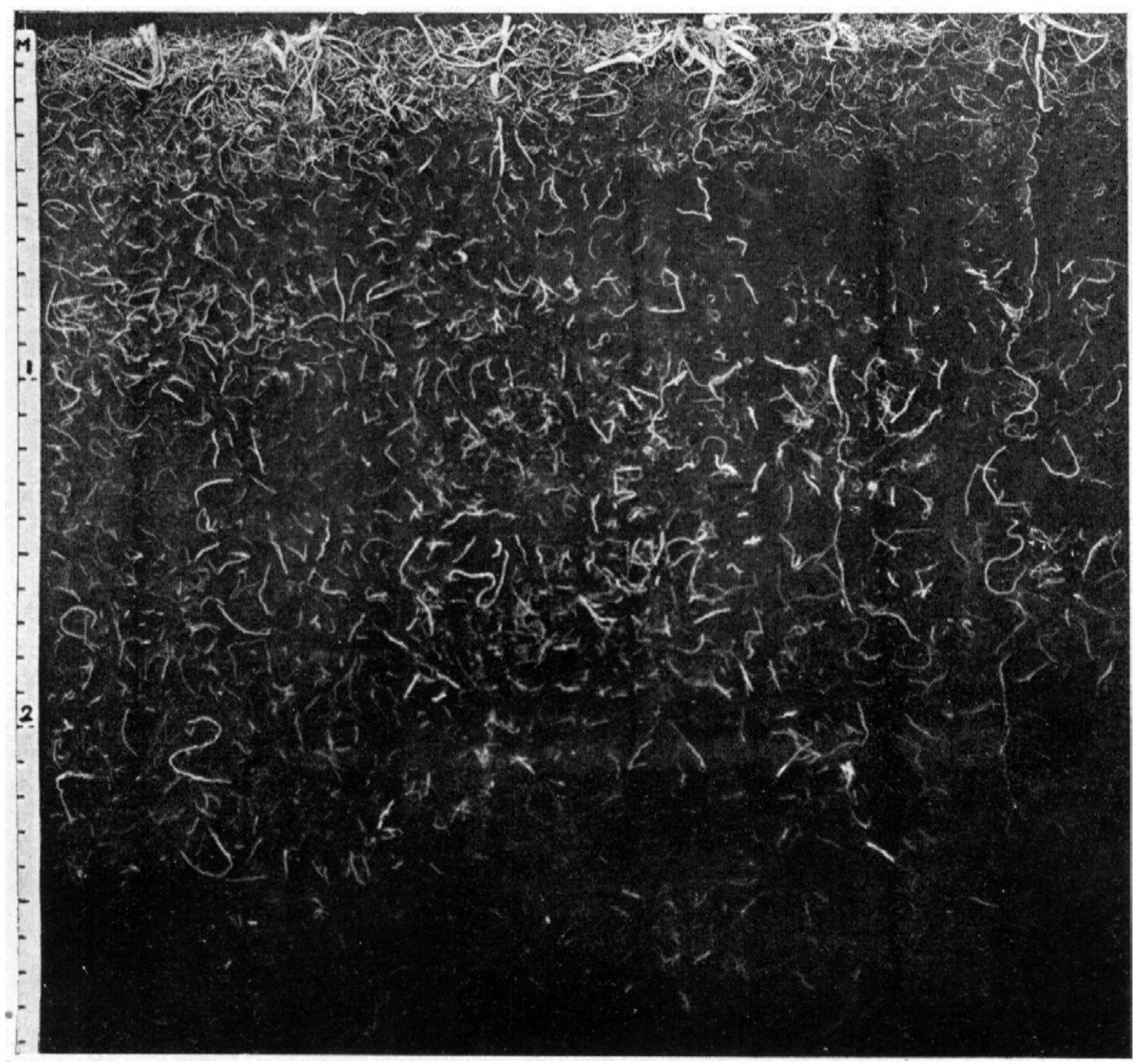

Figura 1 - Sistema radicular do feijão guandu, Cajanus cajan (L.) Millsp. 